\title{
Feasibility of using experimental high viscosity silicone oils: a pilot study
}

\author{
Shira Sheen-Ophir ${ }^{1,2}$, Mordechai Rosner ${ }^{2,3}$ and Alexander Rubowitz ${ }^{1,2^{*}}$
}

\begin{abstract}
Background: Polydimethyl silicones (silicone oils) are used in complex retinal surgeries, including difficult or recurrent retinal detachments, severe eye trauma, and other indications for long term tamponade. Two major problems with currently available silicone oils are emulsification and recurrent retinal detachment. The primary endpoint of this study was to evaluate the toxicity and safety of high viscosity silicone oils and second, the feasibility of using them with currently available vitrectomy systems.

Methods: In this experimental study, 8 eyes of 8 New Zealand White rabbits underwent vitrectomy. The vitreous cavities of 2 eyes were filled with medical grade $5500 \mathrm{cS}$ silicone oil, 4 eyes with 12,500 cS oil, and 2 eyes with 30,000 cS oil for 3 months, after which the animals were sacrificed and the eyes sent for histopathological examination. The duration required to inject 5 cc each of 1300, 12,500 and 30,000 cS oils, using a commercially available system (Alcon VFC Pac) were also evaluated.
\end{abstract}

Results: Retinal histopathology was comparable in all eyes, with no excess toxic effect or damage seen in eyes with experimental oils. All oils were readily injectable with the VFC Pac system.

Conclusions: High viscosity experimental silicone oils have similar chemical and physical properties to lower viscosity oils currently used. Therefore, toxicities are expected to be similar. In a small pilot sample of 8 rabbit eyes filled with silicone oil for 3 months, histopathology in eyes with 12,500, 30,000 cS or medical grade $5500 \mathrm{cS}$ silicone oil were similar. Injecting these oils using available vitrectomy equipment is feasible. New, high viscosity silicone oils may offer several advantages over currently available oils for some patients.

Keywords: Emulsification, Endotamponade, Proliferative vitreoretinopathy, Retinal detachment, Silicone oil

\section{Background}

Polydimethyl silicones (silicone oils) are used for long term endotamponade in complex retinal surgeries, including difficult or recurrent retinal detachments, severe eye trauma, and other indications $[1,2]$. Proliferative vitreoretinopathy (PVR), the most common cause of surgical failure in retinal detachment surgery, occurs in approximately $5-10 \%$ of detachments, and is one of the main uses of long term endotamponade with silicone oil. Two major problems with currently available silicone oils

\footnotetext{
*Correspondence: arubowi@smile.net.il; alex.rubowitz@clalit.org.il ${ }^{1}$ Department of Ophthalmology, Meir Hospital and Sackler Faculty of Medicine, Tel Aviv University, 59 Tchernichovsky St., 44281 Kfar Saba, Israel

Full list of author information is available at the end of the article
}

are emulsification and recurrent retinal detachment $[3$, 4].

Emulsification, the formation of small oil droplets at the interface between oil bubbles and intraocular fluids or tissues, causes dispersion of these droplets into the aqueous and vitreous humors, with consequently higher risk of recurrent detachment, inflammation, secondary glaucoma, and keratopathy [5-7]. Emulsification occurs in $1 \%$ after 1 month, $11 \%$ at 3 months, $85 \%$ at 6 months, and $100 \%$ after 12 months $[4,5]$ and increases with decreasing oil viscosity. However, commercially available $1000 \mathrm{cS}$ and $5000 \mathrm{cS}$ silicone oils may not have clinically significant differences in emulsification [8].

Currently, there is no effective treatment for retinas that detach after placement of silicone oil and a large percentage of these eyes remain chronically detached $[2,4$, 
9-11]. This pilot study examined whether the use of high viscosity silicone oils is safe and feasible using currently available surgical equipment. We intended this as a first step toward examining the possibility of their applicability to provide improved tamponade in cases that failed with currently available silicone oils, and to decrease the incidence of emulsification.

As all dimethyl silicones are chemically identical, the different viscosities of different types of silicone oil arises from the differing lengths of the polymer chains. Increasing the molecular weight of the silicone oil results in a longer polymer chain and increased viscosity [7]. There is therefore, reason to think that high viscosity silicone oils will be as safe and as non-toxic as oils currently in medical use.

We hypothesized that high viscosity silicone oils, ranging from 12,500 to 30,000 centiStokes (cS), in contrast to currently used 1000-5500 cS oils, may provide long-term effective tamponade in patients who experience retinal detachment with currently used silicone oils, possibly with lower risk of long-term emulsification. Towards this end, this pilot study first examined whether silicone oils appear to be as safe and non-toxic to the retina as currently used lower viscosity silicone oils are and second, whether it is practical to inject high viscosity using current vitrectomy equipment.

\section{Methods: overview}

A total of 8 eyes of 8 New Zealand White rabbits weighing 2-3 kg were included in the study. All experiments were approved by the local Animal Research Review Committee and performed in accordance with The Association for Research in Vision and Ophthalmology (ARVO) Statement for the Use of Animals in Ophthalmic and Vision Research (2010/63/EU). One eye only per animal was included, according to ARVO guidelines.

All 8 eyes underwent 23 g pars plana vitrectomy and the vitreous cavity was filled with silicone oil. Three months later, the animals were sacrificed. The eyes were examined histologically for any damage or retinal toxicity by an experienced ocular pathologist (MR).

\section{Methods: surgical procedure}

Prior to surgical procedures, the rabbits were anesthetized by an intramuscular injection of ketamine hydrochloride $(30 \mathrm{mg} / \mathrm{kg})$ and xylazine hydrochloride $(5 \mathrm{mg} /$ $\mathrm{kg}$ ). Pupils were dilated using $2.5 \%$ phenylephrine $/ 0.5 \%$ tropicamide eye drops. Povidone iodine $5 \%$ was applied to the eyelids. In addition, topical anesthesia was administered using several drops of lidocaine $0.4 \%$. Two 23ga trocars, inserted in the superotemporal and superiornasal quadrants $(1.0 \mathrm{~mm}$ posterior to the corneoscleral limbus were used to insert a lighted infusion cannula and a vitrector (Millennium, Bausch \& Lomb, Bridgewater, $\mathrm{NJ}$ ). Under constant infusion of a balanced saline solution, as much vitreous was removed as possible, while avoiding damage to the lens. After fluid-air exchange, the vitreous cavity was filled with silicone oil. Intraocular pressure was not measured.

Subconjunctival injection of gentamicin and betamethasone depot (Celestone Chronodose, MSD) was administered. Moxifloxacin (Vigamox, Alcon, Fort Worth, TX, USA) drops and tobramycin eye ointment (Alcon, USA) were applied locally.

\section{Methods: silicone oils used in the experiment}

Commercially available, industrial grade dimethylsilicone oils (Xiameter, Dow Corning, Midland, MI, USA) were injected into 6 eyes: 4 received 12,500 cS oil [12] and 2 received 30,000 cS oil [13]. Details of the chemical and physical properties of the silicone oils used are listed in Table 1. Boiling point, optical clarity, and refractive index were the same.

The experimental oils were sterilized in an autoclave prior to injection. Two eyes were injected with $5500 \mathrm{cS}$ medical grade, silicone oil (ArcadOphtha, Toulouse, France) currently used clinically.

\section{Methods: histological examination}

Three months after vitrectomy surgery with silicone oil tamponade, the animals were sacrificed. The eyes were enucleated and immediately fixed in $4 \%$ paraformaldehyde. After fixation, the globes were vertically sectioned, processed and embedded in paraffin. The hematoxylin and eosin stained sections were evaluated by an experienced ocular pathologist (MR) using light microscopy.

Table 1 Chemical and physical properties of the silicone oils evaluated

\begin{tabular}{lllll}
\hline Properties & \multicolumn{3}{l}{ Currently used } & \multicolumn{2}{l}{ Tested oils } \\
\hline Viscosity (cS) & 1000 & 5500 & 12,500 & 30,000 \\
Color & & & Colorless & N/A \\
Flash point, open cup $\left({ }^{\circ} \mathrm{C}\right)$ & $>326$ & $>321$ & $>326$ & $>326$ \\
Flash point, closed cup $\left({ }^{\circ} \mathrm{C}\right)$ & $>100$ & $>100$ & $>100$ & $>100$ \\
Hydrophobic & Yes & Yes & Yes & Yes \\
Pour point $\left({ }^{\circ} \mathrm{C}\right)$ & -50 & -50 & -50 & -43 \\
Refractive index & 1.403 & 1.403 & 1.403 & 1.403 \\
Service temperature, high $\left({ }^{\circ} \mathrm{C}\right)$ & 200 & 200 & 200 & 200 \\
Service temperature, low $\left({ }^{\circ} \mathrm{C}\right)$ & -40 & -40 & -40 & -40 \\
Specific gravity @ $25^{\circ} \mathrm{C}$ & 0.971 & 0.975 & 0.975 & 0.971 \\
Surface tension $(\mathrm{mN} / \mathrm{M})$ & 21.2 & 21.4 & 21.5 & 21.5 \\
Thermal conductivity $(\mathrm{W} / \mathrm{mK})$ & 0.159 & 0.159 & 0.159 & N/A \\
Volatile content & & & N/A & N/A \\
\hline
\end{tabular}


The pathologist was blinded to the type of oil inserted into each eye.

\section{Methods: feasibility of using current vitrectomy system}

To examine whether high viscosity silicone oils are readily injectable with the vitrectomy system in use in our hospital (Constellation Vision Systems, Alcon, Fort Worth, TX, USA), we measured the time needed to inject $5 \mathrm{cc}$ of each type of silicone oil, which was taken as an average human vitreous volume, using the VFC Pac and the Constellation Vision System (Alcon, Ft. Worth, TX, USA). The injection times for $1300,12,500$, and $30,000 \mathrm{cS}$ oils, using the 20ga, 23ga, and 25ga injection cannulas supplied with the VFC Pac were measured.

\section{Results}

\section{Histological examination}

Three months after injection with silicone oil, retinal histological examination was performed, including 2 eyes with $5500 \mathrm{cS}, 4$ eyes with $12,500 \mathrm{cS}$ and 2 eyes with $30,000 \mathrm{cS}$ viscosities.

The anterior segments were normal in the two eyes injected with $5500 \mathrm{cS}$ silicone oil. The retina was normal except for artificial changes and inflammatory cells seen in the vitreous cavity of one eye (Fig. 1).

The anterior segment was normal in all four eyes injected with 12,500 cS silicone oil. The retina was unremarkable except for artificial changes in three eyes. A local area with atrophic changes in the anterior retina was seen in one eye (Fig. 2).

The anterior segment was normal in the two eyes injected with $30,000 \mathrm{cS}$ silicone oil. The retina was normal, except for a local equatorial area with atrophic changes and some artificial changes showing thin nuclear layers (Fig. 3).

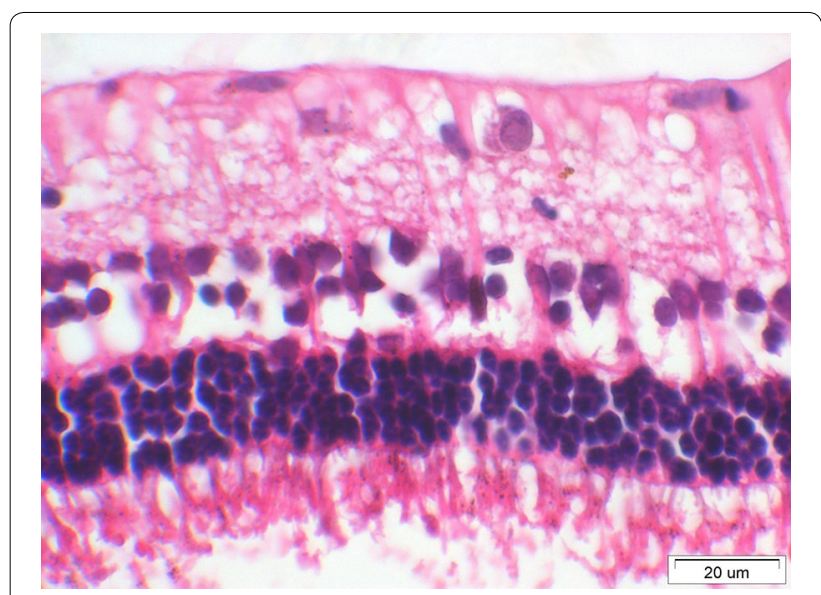

Fig. $1 \mathrm{HE} \times$ 400, retina of an eye injected with 5500 cS silicone oil

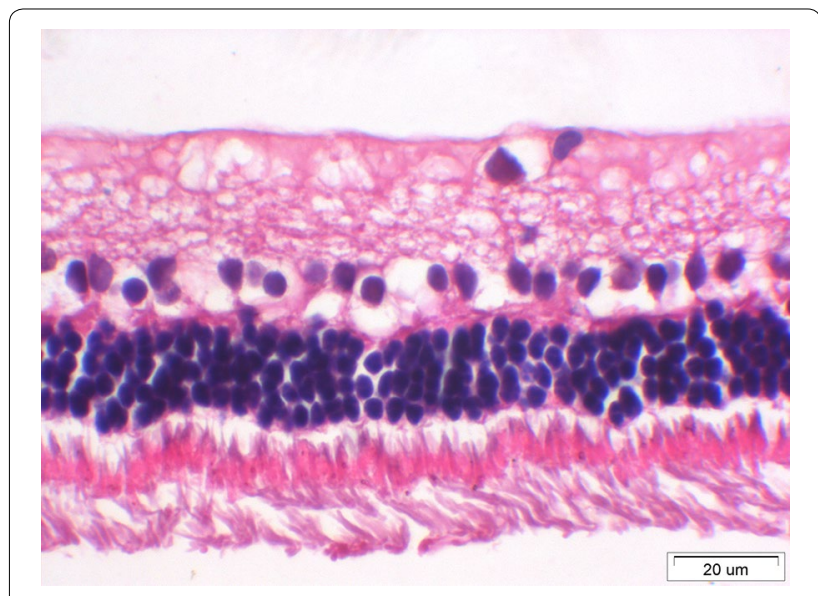

Fig. $2 H E \times 400$, retina of an eye injected with 12,500 cS silicone oil

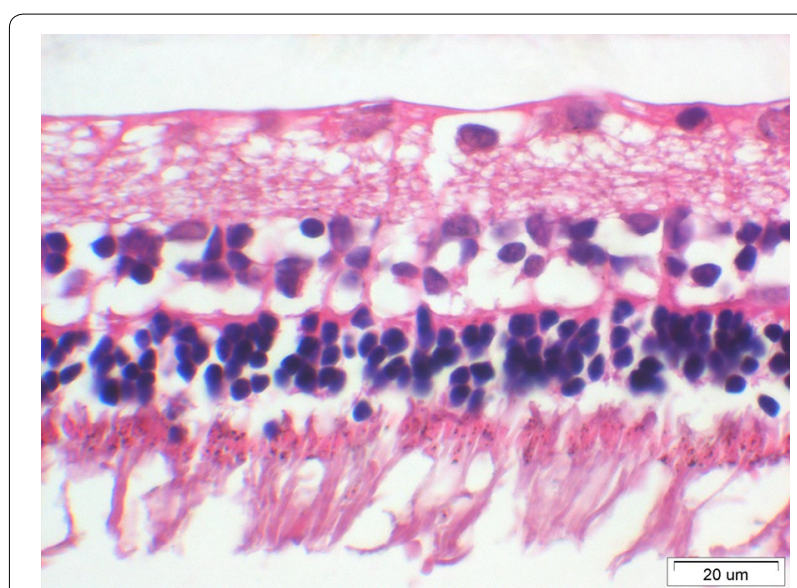

Fig. $3 \mathrm{HE} \times 400$, retina of an eye injected with 30,000 cS silicone oil

Table 2 Injection Times (in seconds) to inject 5 cc for 3 oil viscosities, using the 3 cannula gauges supplied in the VFC PAC

\begin{tabular}{lccc}
\hline Parameters (cS) & \multicolumn{3}{c}{ VFC PAC cannula gauge } \\
\cline { 2 - 4 } & 20ga & 23ga & 25ga \\
\hline 1300 & 30 & 13 & 25 \\
12,500 & 240 & 90 & 180 \\
30,000 & 540 & 180 & 450 \\
\hline
\end{tabular}

\section{Injection times}

The injection times for the 3 different viscosities, using the 3 cannula gauges are shown in (Table 2). Unexpectedly, injection times with the 20ga cannula were longer than they were with the 23ga cannula (Fig. 4). 


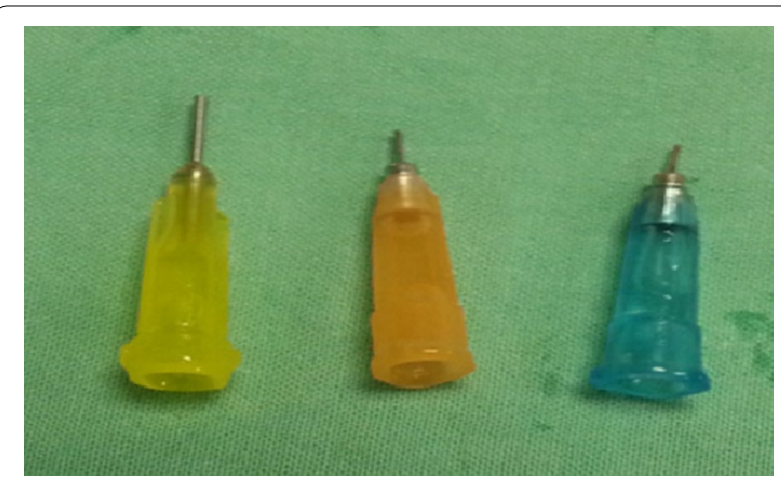

Fig. 4 Alcon VFC Pac silicone oil injection cannulas: left-20ga (yellow), middle-23ga (orange), right-25ga (blue)

\section{Discussion}

This experimental study evaluated the toxicity and safety of using experimental, high viscosity, silicone oils, as well as the feasibility of their use with a currently available vitrectomy system.

Scott et al. compared commercially available 1000 and $5500 \mathrm{cS}$ silicone oils and did not find any clinically significant differences in emulsification [8]. Several in vitro studies demonstrated that higher viscosity silicone oils tend to emulsify less [9-11]. These findings led to several investigations of high viscosity silicone oils [14-18]. However, the silicone oils used in these studies were obtained by adding low concentrations (5-10\%) of long chain silicone molecules to regular silicone oil, and not by using uniformly high viscosity oils, as in the current study. We could not find studies in the literature using pure, unadulterated silicone oil as was used in the current study.

This study used an animal model to demonstrate that 3 months of tamponade with high viscosity 12,500 and 30,000 cS silicone oils was well-tolerated and did not cause excess toxicity compared to medically available $5500 \mathrm{cS}$ silicone oil. This agrees with theoretical expectations, as the chemical and physical properties of these oils are identical. The different viscosities are related only to varying molecular chain lengths.

We also demonstrated that silicone oils with viscosities up to $30,000 \mathrm{cS}$ were readily injectable with a currently available vitrectomy system and that the 23ga cannula required the shortest injection duration. We believe this is because the longer 20ga cannula in the VFC Pac caused greater resistance than the much shorter, 23ga cannula. In addition, we found that with some practice, they are simple to use and do not complicate or significantly prolong surgery. As we expect that these high viscosity oils may be particularly useful in refractory cases of failed and redetached retinas after multiple previous surgeries, adding a few minutes to these last resort surgeries would be a minor inconvenience.

\section{Conclusions}

This pilot study suggests that the high viscosity silicone oils tested may be as safe and nontoxic as currently available oils. We hypothesize that high viscosity oils may be less prone to emulsification complications, and may provide effective tamponade in patients who experienced detachment after receiving lower viscosity silicone oils. Therefore, we are continuing to study the properties and use of these oils in retinal detachment.

\section{Authors' contributions \\ SS, MR and AR conceived and designed the study. SS, MR performed the surgeries and acquired the data. SS, MR and AR reviewed and synthesized the literature and analyzed and interpreted the data. SS, MR drafted the manuscript. MR, AR critically reviewed and revised the draft manuscript. All authors read and approved the final manuscript and agree to be accountable for all aspects of the work in ensuring that questions related to the accuracy or integrity of any part of the work are appropriately investigated and resolved. All authors read and approved the final manuscript. \\ Author details \\ ${ }^{1}$ Department of Ophthalmology, Meir Hospital and Sackler Faculty of Medi- cine, Tel Aviv University, 59 Tchernichovsky St., 44281 Kfar Saba, Israel. ${ }^{2}$ Depart- ment of Ophthalmology, Sackler Faculty of Medicine, Tel Aviv University, Tel Aviv, Israel. ${ }^{3}$ Goldschleger Eye Institute, Sheba Medical Center, Tel Hashomer, Israel.}

\section{Competing interests}

The authors declare that they have no competing interests.

Previous presentations: 33rd ASRS Conference in Vienna, Austria, July 2015.

\section{Availability of data and materials}

Data can be accessed upon request from the corresponding author.

\section{Consent for publication}

Not applicable.

\section{Ethics approval}

All experiments were approved by the local Animal Research Review Committee and performed in accordance with The Association for Research in Vision and Ophthalmology (ARVO) Statement for the Use of Animals in Ophthalmic and Vision Research (2010/63/EU).

\section{Funding}

This research received no specific grant from any funding agency in the public, commercial, or not-for-profit sectors.

\section{Publisher's Note}

Springer Nature remains neutral with regard to jurisdictional claims in published maps and institutional affiliations.

Received: 29 May 2017 Accepted: 25 December 2017

Published online: 08 January 2018

References

1. Fraser S, Steel D. Retinal detachment. BMJ Clin Evid. 2009;2009:0710.

2. Saxena S, Gopal L. Fluid vitreous substitutes in vitreo retinal surgery. Indian J Ophthalmol. 1996;44:191-206 (Review) 
3. Wagenfeld L. Long-lasting endotamponades in vitreoretinal surgery. Ophthalmologica. 2010;224:291-300.

4. Sharma T. Management of recurrent retinal detachment in silicone oilfilled eyes. Retina. 2002;22:153-7.

5. Federman JL. Complications associated with the use of silicone oil in 150 eyes after retina-vitreous surgery. Ophthalmology. 1988;95:870-6.

6. Chan C, Okun E. The question of ocular tolerance to intravitreal liquid silicone: a long-term analysis. Ophthalmology. 1986;93:651-60.

7. Barca F, Caporossi T, Rizzo S. Silicone oil: different physical proprieties and clinical applications. Biomed Res Int. 2014;2014:502143. https://doi. org/10.1155/2014/502143.

8. Scott IU, Flynn HW Jr, Murray TG, Smiddy WE, Davis JL, Feuer WJ. Outcomes of complex retinal detachment repair using 1000-versus 5000-centistoke silicone oil. Arch Ophthalmol. 2005;123:473-8.

9. Yamamoto S, Takeuchi S. Silicone oil and fluorosilicone. Semin Ophthalmol. 2000;15:15-24.

10. Abrams GW. Vitrectomy with silicone oil or long-acting gas in eyes with severe proliferative vitreoretinopathy: results of additional and long-term follow-up. Silicone Study report 11. Arch Ophthalmol. 1997;115:335-44.

11. Heidenkummer H, Kampik A, Thierfelder S. Emulsification of silicone oils with specific physiochemical characteristics. Graefe's Arch Clin Exp Ophthalmol. 1991;229:88-94.
12. Xiameter ${ }^{\circledR}$ PMX-200 Silicone Fluid 12,500 CS https://www.xiameter.com/ EN/Pages/RetrieveDocument.aspx?type $=$ SDS\&Documentld $=090277018$ 379527d\&s=290700. Accessed 26 Sept 2017.

13. Xiameter ${ }^{\circledR}$ PMX-200 Silicone Fluid 30,000 CS https://www.xiameter.com/ EN/Pages/RetrieveDocument.aspx?type $=$ SDS\&Documentld $=090277018$ 37a9515\&s=290700. Accessed 26 Sept 2017.

14. Williams RL, Day M, Garvey MJ, English R, Wong D. Increasing the extensional viscosity of silicone oil reduces the tendency for emulsification. Retina. 2010;30:300-4.

15. Caramoy A, Schröder S, Fauser S, Kirchhof B. In vitro emulsification assessment of new silicone oils. Br J Ophthalmol. 2010;94:509-12.

16. Williams RL, Day MJ, Garvey MJ, et al. Injectability of silicone oil-based tamponade agents. Br J Ophthalmol. 2011;95:273-6.

17. Caramoy A, Hagedorn N, Fauser S, Kugler W, Gross T, Kirchhof B. Development of emulsification-resistant silicone oils: can we go beyond 2000 mPas silicone oil? Invest Ophthalmol Vis Sci. 2011;52:5432-6.

18. Kei CY, David W. The effect of viscosity of PDMS based silicone-oil tamponade agents on the movement relative to the eye wall during eye movements. i-Perception. 2011;2(4):338.

\section{Submit your next manuscript to BioMed Central and we will help you at every step:}

- We accept pre-submission inquiries

- Our selector tool helps you to find the most relevant journal

- We provide round the clock customer support

- Convenient online submission

- Thorough peer review

- Inclusion in PubMed and all major indexing services

- Maximum visibility for your research

Submit your manuscript at www.biomedcentral com/submit 